\title{
Letter from . . . America
}

\section{Providing services for drug misusers: what lessons from North America?}

\author{
P M FLEMING
}

New York has the largest number of intravenous drug users in the United States. As there is a high prevalence of infection from human immunodeficiency virus (HIV) among this group the city has had to confront issues that will face others in the future. ${ }^{12}$ Health professionals have had to look at ways of reducing high risk behaviour among intravenous drug users, such as using and sharing dirty syringes and needles, and there is some evidence that addicts are changing their behaviour. ${ }^{34}$ These changes are insufficient, however, and those most at risk-young intravenous drug usersseem most resistant to change.

Only a proportion of drug users are in contact with the treatment services and great efforts have been made to try and reach the rest. ${ }^{5}$ This is a group to which we in the United Kingdom will need to pay attention. The National Institute on Drug Abuse (part of the United States Department of Health and Human Services) is funding two AIDS demonstration projects. ${ }^{6}$ In one, multiple outreach or early intervention methods will be used to try to communicate information on AIDS to high risk individuals in five cities. In the other different outreach models will be evaluated to find which work best in reaching different target populations. In New York drug users, exusers, and health professionals have set up the Association for Drug Abuse, Prevention, and Treatment to educate addicts about AIDS, give support to the sick, and try to reduce the spread of HIV by drug users. ${ }^{7}$ As a result of such efforts more drug users are coming forward for treatment than the services can cope with. ${ }^{5}$ The methadone programme in New York is oversubscribed and there are waiting lists for treatment. The concern is that if treatment is not available addicts will disappear and the efforts to reduce HIV infection will be undermined. Similar pressures could occur in the United Kingdom.

The rehabilitation services in the United States are having to cope with dying patients as AIDS presents in residents in drug rehabilitation units and among ex-addict staff members. We will also have to train and support staff to deal with these problems.

\section{Substance misuse by adolescents}

As the number of young people with drug and alcohol problems increases in the United States so do the services available to help them. ${ }^{8}$ But inpatient treatment is mainly in the private sector and so is available only to those with comprehensive insurance or the means to pay. Because it is expensive inpatient treatment is limited

Wessex Regional Drug Dependency Services, Portsmouth PO6 3EP

P M FLEMING, FRCPSYCH, consultant psychiatrist

Correspondence to: Wessex Regional Drug Dependency Services, Northern Road Clinic, Northern Road, Cosham, Portsmouth PO6 3EP. to about four weeks. Most young abusers are seen as outpatients with a small proportion of them being treated in residential, nonmedical units. During my visit the services that I saw were usually well structured. They placed clear limits on the adolescents' behaviour and sometimes used behaviour therapy techniques. There was usually individual, group, and family therapy, and often close liaison with schools. Phoenix House in New York-a long established drug abuse agency-has developed several residential and outpatient programmes for adolescent drug users. ${ }^{9}$ In one programme-Intervention Moves Parents and Children Together (IMPACT)-adolescents attend every afternoon after school and are placed on "house arrest" when at home for the first 30-90 days. They are continually supervised by a parent and are not allowed to associate with old drug using friends. The parents have to attend weekly seminars and are asked not to use alcohol or drugs in front of their children.

\section{Addiction Research Foundation of Ontario}

The Toronto based Addiction Research Foundation of Ontario is a government agency and a centre of international repute for research into addictions. ${ }^{10}$ It also provides treatment services for the province of Ontario, is an educational institution, and undertakes prevention activities. Its effectiveness derives from the integration of research, service provision, and education. Because of the research background of many of the foundation's activities there is an emphasis on evaluating services and ensuring that they are developed and take into account up to date research findings. We could usefully look at this model in the United Kingdom where addiction services are rarely rigorously evaluated.

An example of this policy is the development of the addiction services policy for the province of Ontario. ${ }^{112}$ This is based on the foundation's action plan, which was developed after research showed the effectiveness of community based services for addicts. The plan proposed a comprehensive community based service to increase awareness of the importance of early identification; to promote standardised assessment techniques; and to ensure that services were developed by coordinating and mobilising existing community resources.

In the United States and in Ontario the requirements for services are spelt out in much more detail than in the United Kingdom. In some American states the requirements form part of the mental hygiene law-those covering the services in New York state run to 77 pages. In the United Kingdom we have given more independence and less direction to those who run services for drug users-for example, consultants in charge of clinical services and the nonstatutory agencies responsible for a wide variety of residential and non-residential programmes. As a result we have lost the opportunity to evaluate and compare services. It would be useful to look at ways of standardising assessment and review procedures. 


\section{Employee assistance programmes}

Employee assistance programmes have been developed to help identify, manage, and treat employees who have an addiction problem which leads to family and work related difficulties. The latter include absenteeism, lateness, poor work record, accidents, low productivity, and so on. A greater awareness of the need for such services is evident in North America, and they are more highly developed than in the United Kingdom. In Phoenix House in New York clients are in residence for about 90 days; for the first 30 or so they are off work. They resume work from the unit, using it as a hostel, and continue to receive counselling and support. After discharge participants return for evening group meetings whose frequency gradually diminishes over the following nine months. The total treatment time is more than a year.

In Canada the community services division of the Addiction Research Foundation allocates $30 \%$ of its budget to employee assistance programmes. The staff work with a large number of organisations to help establish policies and train management and staff. One contentious issue has been that of the compulsory screening of employees for the presence of drugs. ${ }^{13}$

\section{Services for addicted professionals}

I was impressed with the development of services for addicted professionals in both the United States and Canada. The treatment programmes seemed better organised and monitored, and the services are more accessible than in the United Kingdom. In Ontario the Addiction Research Foundation together with the Ontario physicians and surgeons developed a comprehensive programme of research, education, and treatment in 1977. More recently the professions of medicine, nursing, pharmacy, dentistry, and veterinary medicine have cooperated to form the Ontario Health Professionals Assistance Programme. Professionals referred to this programme undergo a comprehensive standardised assessment and are then referred for the most appropriate treatment. In New York the State Division of Substance Abuse (a state funded organisation) has an office in Manhattan with eight staff who provide services for "licensed" professionals in New York state with addiction problems. This includes people with professional qualifications who are allowed to practise in the state of New York, such as doctors, lawyers, pharmacists, and nurses.

\section{Conclusion}

The United States has a markedly greater drug problem than the United Kingdom, and Canada has less of a problem than the United Kingdom. The health care systems and the traditions of medicine are different, and this influences the way that the services develop. Despite these differences, however, we all face the same basic problems. A much higher priority is placed on research and evaluation in North America. For example, the bulk of the National Institute on Drug Abuse's budget is spent on clinical trials and outcome research. And research and evaluation are an important part of the work of the Addiction Research Foundation in Canada.

The message that came over loud and clear during my visit to North America was that the planning of services must be closely integrated with relevant research and that the services must be evaluated. We would do well to heed this message.

I thank Wessex Regional Health Authority for financial help with my visit to New York, Washington, and Toronto.

\section{References}

1 Des Jarlais DC, Friedman SR, Strug D. AIDS and needle sharing within the IV drug use subculture. In: Feldman D, Johnson T, eds. The social dimensions of AIDS. New York: Praeger, 1986

2 Marmor M, Des Jarlais DC, Cohen H, et al. Risk factors for infection with AIDS among IV drug abusers in New York city. AIDS: An International fournal 1987;1(1):39-44.

3 Des Jarlais DC, Friedman SR. Target groups for preventing AIDS among IV drug users. fournal of Applied Social Psychology 1987;17:251-68.

4 Friedman SR, Des Jarlais DC, Southeran JL. AIDS health education for IV drug users. Health Educ $Q$ 1986;13(4):383-93.

5 Hartsock PH. AIDS-related initiatives and issues concerning US drug abusers. WHO consultation on AIDS and drug abuse, Stockholm, October 1986.

6 Nation Institute on Drug Abuse. NIDA's AIDS demonstration projects. New York: National Institute on Drug Abuse, 1987.

7 Friedman SR, Des Jarlais DC, Southeran JL, Garber J, Cohen H, Smith D. AIDS and self organisation among IV drug users. Int $\mathcal{F}$ Addict 1987;22(3):201-19.

8 Beschner G. Treatment for childhood chemical abuse. In: Griswold-Ezekoye S, Kumpfer KL, Bukoski WJ, eds. Childhood and chemical abuse: prevention and intervention. New York: Haworth Press, 1986.

9 Phoenix House Incorporated. Phoenix House annual report 1985/86. New York: Phoenix House Incorporated, 1986.

10 Cappell HD. The addiction research foundation of Ontario. Br $\mathcal{A}$ Addic 1987;82:1081-9.

11 Addiction Research Foundation. Interface agreement between Ministry of Health's community health services operations branch and addiction research foundation's community services division. Toronto: Addiction Research Foundation, 1986.

12 Ministry of Health. Addictions services policy. Toronto: Ministry of Health, 1986.

13 Addiction Research Foundation. Employee-related drug screening. Best advice. Toronto: Addiction Research Foundation, 1987

(Accepted 8 February 1988)
What advantages has phakoemulsification over intracapsular or extracapsular removal of a cataract?

Cataracts may be removed in several ways. The two most commonly used methods in Britain are intracapsular cataract surgery, in which the lens is removed intact within its capsule, and extracapsular cataract extraction, in which the nucleus is expressed and the cortical matter of the lens carefully removed, leaving the posterior capsule as a membrane that retains the vitreous. Intracapsular cataract surgery, which in the 1960s and '70s was the most commonly performed technique for treating cataracts, is a safe and well tried method that gives excellent visual results. Its serious complications, however, include loss of vitreous, which carries a significant risk of subsequent retinal detachment. With the evolution and development of intraocular lens design and much improved techniques for performing extracapsular surgery Britain has seen a swing to extracapsular away from intracapsular techniques.

Phakoemulsification is a form of extracapsular cataract surgery, but instead of expressing the nucleus the opaque lens is removed by ultrasonically emulsifying and then aspirating it from the eye. In contrast with intracapsular and extracapsular cataract extraction phakoemulsification requires a much smaller incision, just big enough to allow an ultrasonic probe and its coaxial infusion sleeve to enter the eye. Wound closure is simple, quick, and more immediately stable than after the larger incisions of conventional surgery and thus more patients are fully active more quickly. In experts' hands the technique allows speedy and safe surgery, and it is particularly popular in the United States, where day case cataract surgery is the rule. The technique requires an extended training period and expensive equipment. Severe damage to the cornea has been caused by appreciable temperature rises within the eye from prolonged use of the ultrasonic probe. Mechanical damage may also occur from uncontrolled spinning of the hard lens nucleus and from the ultrasonically excited lens fragments that pelt the corneal endothelium. In summary, phakoemulsification is an expensive, technologically complicated way of doing extracapsular cataract extractions and brings its own set of complications to such extraction, which is accepted as the safest form of cataract surgery.-B A NOBLE, consultant ophthalmologist, Leeds.

Weinstein G. Cataract surgery: clinical ophthalmology. Vol 5. Philadelphia: Thomas Duane, 1984 19-20.

Beckett R. Cataract surgery and IOL in the UK in 1986. European fournal of Implant and Refractive Surgery 1988;5:52-8.

\section{Does heavy lifting aggravate a hiatus hernia?}

As it is not clear, in any case, why hiatus hernias occur it is impossible to know what factors might enlarge them. The size of a sliding hiatus hernia, however, is of little importance, and such hernias are not subject to strangulation and incarceration. What matters to the patient is the severity of gastro-oesophageal reflux, and this undoubtedly is increased by bending and other manoeuvres that increase intra-abdominal pressure.-J R BENNETT, consultant gastroenterologist, Hull. 